\title{
Neural Correlates of Alzheimer's Disease and Mild Cognitive Impairment: A Systematic and Quantitative Meta-Analysis involving 1,351 Patients
}

\author{
Matthias L. Schroeter ${ }^{a, b}$, Timo Stein ${ }^{c, d}$, Nina Maslowski ${ }^{a}$, and Jane Neumann ${ }^{a}$ \\ aMax-Planck-Institute for Human Cognitive and Brain Sciences, Stephanstr. $1 \mathrm{~A}$ \\ ${ }^{b}$ Day Clinic of Cognitive Neurology, University of Leipzig, Liebigstr. 22A, 04103 Leipzig \\ 'Department of Psychology, Ludwig-Maximilians-University, Leopoldstr. 13, 80802 München, \\ Germany \\ ${ }^{\mathrm{d} D e p a r t m e n t}$ of Psychology, Princeton University, Green Hall, Princeton, 08540 New Jersey; USA
}

\begin{abstract}
Alzheimer's disease is the most common form of dementia. Its prodromal stage amnestic mild cognitive impairment is characterized by deficits of anterograde episodic memory. The development of standardized imaging inclusion criteria has to be regarded as a prerequisite for future diagnostic systems. Moreover, successful treatment requires isolating imaging markers predicting the disease. Accordingly, we conducted a systematic and quantitative meta-analysis to reveal the prototypical neural correlates of Alzheimer's disease and its prodromal stage. To prevent any a priori assumptions and enable a data-driven approach only studies applying quantitative automated whole brain analysis were included. Finally, 40 studies were identified involving 1,351 patients and 1,097 healthy control subjects reporting either atrophy or decreases in glucose utilization and perfusion. The currently most sophisticated and best-validated of coordinate-based voxel-wise meta-analyses was applied (anatomical likelihood estimates). The meta-analysis reveals that early Alzheimer's disease affects structurally the (trans-)entorhinal and hippocampal region, functionally the inferior parietal lobules and precuneus. Results further may suggest that atrophy in the (trans-)entorhinal area/hippocampus and hypometabolism/hypoperfusion in the inferior parietal lobules predict most reliably the progression from amnestic mild cognitive impairment to Alzheimer's disease, whereas changes in the posterior cingulate cortex and precuneus are unspecific. Fully developed Alzheimer's disease involved additionally a frontomedian-thalamic network. In conclusion, the meta-analysis characterizes the prototypical neural substrates of Alzheimer's disease and its prodromal stage amnestic mild cognitive impairment. By isolating predictive markers it enables successful treatment strategies in the future and contributes to standardized imaging inclusion criteria for Alzheimer's disease as suggested for future diagnostic systems.
\end{abstract}

Corresponding author: Matthias L. Schroeter, MD, PhD, MA, Max-Planck-Institute for Human Cognitive and Brain Sciences, Stephanstr. 1A, 04103 Leipzig, Germany, email: schroet@ cbs.mpg.de, phone: ++49-341-9724962, fax: ++49-341-9724989.

Supplementary Information: Tables S1-S3 describe the characteristics and Figures S1-S3 show the maxima of the several studies, which were included in the meta-analysis.

Publisher's Disclaimer: This is a PDF file of an unedited manuscript that has been accepted for publication. As a service to our customers we are providing this early version of the manuscript. The manuscript will undergo copyediting, typesetting, and review of the resulting proof before it is published in its final citable form. Please note that during the production process errors may be discovered which could affect the content, and all legal disclaimers that apply to the journal pertain. 


\section{Introduction}

Alzheimer's disease (AD) is the most common form of dementia (Blennow et al., 2006; Cummings, 2004). Its prevalence is below $1 \%$ in individuals aged 60-64 years, but shows an almost exponential increase with age, so that in people aged 85 years or older the prevalence is between $24 \%$ and $33 \%$ in the Western world. In 2001, more than 24 million people had dementia, a number that is expected to double every 20 years up to 81 million in 2040. Accordingly, $\mathrm{AD}$ is a major public health problem. The majority of patients suffer from sporadic $\mathrm{AD}$, whereas familial $\mathrm{AD}$ is a very rare autosomal dominant disease with early onset before 48 years of age and prevalence below $0.1 \%$ (Reisberg, 2006). AD is a slowly progressive disorder, with insidious onset and early impairment of episodic memory; other signs include impaired judgment, decision-making, orientation, aphasia, apraxia, and agnosia (Blennow et al., 2006; Caselli et al., 2006; Hodges, 2006). Histopathological changes consist of amyloid $\beta$ aggregation and deposition in senile or neuritic plaques, and of tau hyperphosphorylation with formation of neurofibrillary tangles in medial temporal and other cortical regions, starting already 20-30 years before clinical onset and finally injuring neurons and synapses (Blennow et al., 2006).

The preclinical phase is designated amnestic mild cognitive impairment (MCI) (Gauthier et al., 2006; Petersen et al., 1999, 2001a, 2001b, 2004; Schott et al., 2006). It is defined as memory complaints and deficits, which are greater than expected for an individual's age and education level but do not interfere notably with activities of daily life such as in dementia. Some people with MCI remain stable or return to normal over time, but more than half progress to dementia within 5 years. Because the identification of $\mathrm{MCI}$ as a risk state for $\mathrm{AD}$ might enable disease modifying treatment strategies in the future, one of the most important challenges for neuroimaging is discriminating MCI patients progressing later to AD from patients who will not (Chong and Sahadevan, 2005; Gauthier et al., 2006; Klafki et al., 2006; Schott et al., 2006).

Internationally accepted ante mortem diagnostic criteria for $\mathrm{AD} / \mathrm{MCI}$ are based on clinical symptoms (American Psychiatric Association, 1987, 1994; McKhann et al., 1984; Petersen et al., 1999, 2001a, 2001b, 2004; World Health Organization, 1993). These criteria have now fallen behind the unprecedented growth of scientific knowledge regarding biomarkers for $\mathrm{AD} /$ $\mathrm{MCI}$, namely structural and functional neuroimaging. It was proposed to incorporate these biomarkers into revised diagnostic criteria in the future (Dubois et al., 2007; Hyman, 2007; Reisberg, 2006).

Accordingly, one aim of the present meta-analysis was to characterize the prototypical neural substrates of $\mathrm{AD}$ and its prodromal stage amnestic MCI. We applied the systematic and quantitative meta-analytic approach as suggested by Turkeltaub et al. (2002), which is considered the most sophisticated and best-validated of coordinate-based voxel-wise metaanalyses (Fox et al., 2005). This method can extract the prototypical neural networks for AD and MCI, because it considers only peak coordinates for each region, whether small or large. We included morphometric studies investigating brain atrophy with magnetic resonance imaging (MRI) and imaging studies measuring reduction in glucose utilization or in perfusion with positron emission tomography (PET) or single photon emission computed tomography (SPECT) during rest. Moreover, we wanted to isolate neural markers predicting conversion from amnestic MCI to AD. Because AD progressively impairs episodic memory (Blennow et al., 2006; Hodges, 2006), we hypothesized alterations in the medial temporal lobes, medial diencephalon, parietal cortex and prefrontal regions (Braak and Braak, 1991a, 1991b, 1995; Braak et al., 1996; Brand and Markowitsch, 2005; Cabeza and Nyberg, 2000; Cavanna and Trimble, 2006; Hyman et al., 1984; Petersen et al., 2006; Wagner et al., 2005). Furthermore, 
we postulated that alterations of these brain regions may predict conversion from amnestic $\mathrm{MCI}$ to AD.

\section{Materials and Methods Data Sources \& Study Selection}

MedLine and Current Contents search engines were used to identify studies on morphometry, glucose utilization and perfusion in AD and MCI (search strategy: [Alzheimer or [mild and cognitive and impairment]] and [MRI or MRT or PET or SPECT]) published until February 2007. Primary authors were contacted to obtain additional information if necessary. Studies were examined to fulfill the following inclusion criteria: peer-reviewed, original studies, patients diagnosed according to internationally recognized diagnostic criteria (criteria for probable AD according to the National Institute of Neurological and Communicative Disorders and Stroke and the Alzheimer's Disease and Related Disorders Association, NINCDSADRDA, McKhann et al., 1984; research criteria as suggested in the $10^{\text {th }}$ version of the International Classification of Diseases System, World Health Organization, 1993; or by the Diagnostic and Statistical Manual of Mental Disorders, DSM-III-R DSM-IV, American Psychiatric Association, 1987, 1994; criteria for amnestic MCI according to Petersen or the Mayo Clinic Alzheimer's Disease Research Center, Petersen et al., 1999, 2001a, 2001b, 2004), patients compared to age-matched healthy controls, quantitative automated whole brain analysis method, results normalized to a stereotactic space such as the Talairach or the Montreal Neurological Institute (MNI) reference system, and respective co-ordinates are available. When maxima were reported in the MNI reference system, they were transformed to the Talairach space according to a formula proposed by Matthew Brett (published in the internet: http://www.mrc-cbu.cam.ac.uk/Imaging/common/mnispace.shtml). Amnestic MCI was defined by criteria developed by Petersen et al. (1999, 2001a, 2001b, 2004) or by memory complaint, objective impairment in memory or in one other area of cognitive function in two perfusion studies (Hirao et al., 2005; Huang et al., 2003), and one MRI study (Pennanen et al., 2005). Studies had to fulfill the following exclusion criteria: no solely region-of-interest analysis to prevent any a priori assumptions with regard to the involved neural networks and to enable a data-driven approach, no case studies, no familial and visual variant AD (posterior cortical atrophy) as they may constitute other types of AD compared to sporadic, non-familial $\mathrm{AD}$, and no studies investigating substantially overlapping patient populations. Moreover, we excluded generally functional imaging studies investigating brain activation during cognitive stimulation, because they apply diverse psychological paradigms hampering quantitative metaanalytic techniques. Although medication might influence brain metabolism and perfusion, we could not include this issue in the exclusion criteria, because only a few studies $(24 \%)$ contained respective information.

\section{Data Abstraction \& Study Characteristics}

Literature search, selection of studies according to the inclusion and exclusion criteria and compilation of coordinates for the several contrasts were performed independently by two investigators (T.S. and N.M.) and any disagreements were resolved by consensus. We focused on the differences between patients with $\mathrm{AD}$ or MCI and healthy controls. Additionally, we involved studies examining patients with MCI, of whom some progressed later to AD (converter) and some not (non-converter). Contrasts between patients and healthy volunteers were included reporting either atrophy $(\mathrm{MRI})$, decreases in glucose utilization $\left({ }^{18} \mathrm{~F}\right.$ fluorodeoxyglucose-[FDG]-PET) or perfusion $\left(\mathrm{H}_{2}{ }^{15} \mathrm{O}-\mathrm{PET},{ }^{99 \mathrm{~m}} \mathrm{Tc}\right.$ hexamethylpropyleneamine oxime-[HMPAO]-SPECT, ${ }^{99 \mathrm{~m}} \mathrm{Tc}$-ethylcysteinate dimmer[ECD]-SPECT). Only three studies reported brain regions of either relatively increased glucose utilization (AD: Salmon et al., 2000) or perfusion (AD: Kogure et al., 2000; MCI: Huang et al., 2003) in the patient groups if compared with control subjects. Because the other numerous 
studies did not show such alterations, its influence on the meta-analysis may be regarded as negligible.

\section{Quantitative Data Synthesis}

We applied the anatomical likelihood estimate meta-analysis method (Ellison-Wright et al., 2008; Glahn et al., 2008; Schroeter et al., 2007b, 2008; Turkeltaub et al., 2002). The idea behind this method is to determine brain regions that exhibit a higher density of peak coordinates reported across studies than would arise by chance. As the accuracy of peak coordinates reported in different imaging studies is limited, for example, by anatomical intersubject variability, data smoothing, or the use of different brain templates (Eickhoff et al., 2009; Turkeltaub et al., 2002), peak coordinates should not be viewed as single points but rather as localization probability distributions centered at these coordinates. Thus, peaks of atrophy, hypometabolism or hypoperfusion were modeled using a 3D Gaussian probability distribution

$$
p=\frac{1}{[2 \pi]^{1.5} \sigma^{3}} e^{\frac{-d^{2}}{2 \sigma^{2}}}
$$

where $\sigma$ is the standard deviation for the Gaussian and $\boldsymbol{d}$ is the Euclidean distance of a voxel to the peak. For a particular voxel and a given peak with distance $\boldsymbol{d}, \boldsymbol{p}$ can be viewed as an estimate for the likelihood that the given peak lies within this voxel (Turkeltaub et al., 2002). After calculating this anatomical likelihood estimate (ALE) for each voxel and each peak, an ALE map can be created, representing for each voxel the likelihood that at least one of the reported peaks is located there (Turkeltaub et al., 2002). Specifically, given two likelihood estimates $\boldsymbol{p}_{\boldsymbol{a}}$ and $\boldsymbol{p}_{\boldsymbol{b}}$, representing the likelihood that peak $\boldsymbol{a}$ and peak $\boldsymbol{b}$ lie within a particular voxel $\boldsymbol{x}$, respectively, the ALE representing the likelihood that at least one of the two peaks lies within this voxel $\boldsymbol{x}$ can be calculated as

$$
\mathrm{ALE}_{x}=p_{a}+p_{b}-p_{a} p_{b}=p_{a}+p_{b}\left(1-p_{a}\right)
$$

For more than two peaks, the equation can be applied iteratively.

We wanted to examine the neural correlates of $\mathrm{AD}$ and amnestic MCI, and to explore the subtle distinction between patients with amnestic MCI converting later to AD (converter) and those who maintain the diagnosis MCI (non-converter). Hence, we created separate ALE maps for the coordinates from studies involving subjects with AD, subjects with amnestic MCI, and subjects that convert from amnestic MCI to AD. Because it is controversial whether functional alterations and atrophy coincide anatomically in dementia (Ishii et al., 2005; Nestor et al., 2003), the ALE maps were calculated separately for the three imaging methods controlling for confounding effects. Only for the contrast converters vs. non-converters (from amnestic MCI to AD) MRI, FDG-PET and perfusion studies had to be pooled to include a sufficient number of studies. ALE values were determined on a grid of isotropic $2 \times 2 \times 2 \mathrm{~mm}$ voxels. We used a standard deviation of $5 \mathrm{~mm}$ resulting in a full-width half-maximum of $11.8 \mathrm{~mm}$. This distribution width was chosen to approximately match filter sizes commonly used in anatomical MRI, FDG-PET and perfusion studies, and to match the potential bias of the MNI-Talairach space transformation by Matthew Brett (Chau and McIntosh, 2005).

In a second step, empirical ALE maps from the different groups were compared to ALE maps for randomly distributed maxima. The same number of maxima as included in the empirical ALE map was uniformly distributed 1,000 times over a brain volume mask. Histograms of the 
thousand sets of randomly distributed maxima were averaged to obtain a histogram representing the noise distribution of ALE values. This histogram served as a null hypothesis against which the significance of the empirical ALE values was tested. As in the study by Turkeltaub et al. (2002), a conservative ALE threshold corresponding to a level of $0.01 \%$ $(\mathrm{p}<0.0001)$ was chosen to reduce the probability of type I errors and to identify only the most consistent regions of atrophy, hypometabolism and -perfusion. The null hypothesis of random distribution was rejected for those voxels that exceeded this threshold.

\section{Results}

\section{Trial Flow \& Study Characteristics}

Figure 1 shows the meta-analysis flow. The initial search yielded for MCI/AD 311/1703 studies. Finally, 14/26 studies met inclusion and exclusion criteria and were included into the meta-analysis (Tables S1 to S3 in the supplementary information). Table 1 illustrates the number of studies, the number of subjects and clinical characteristics for the several groups. In sum, 1,351 patients (826 with AD, 525 with amnestic MCI) and 1,097 healthy control subjects were involved in the meta-analysis. We conducted an ANOVA analysis with two factors, diagnosis (AD vs. MCI) and method (MRI vs. FDG-PET vs. perfusion) to test differences in scores of the Mini Mental State Examination. As expected, patients with amnestic MCI showed higher mean scores than patients with $\mathrm{AD}(\mathrm{df}=1, \mathrm{~F}=64.5, \mathrm{p}<0.001)$ for each of the imaging methods (1-tailed post hoc Student's t-tests, $\mathrm{p}<0.001$, respectively). There was no influence of the main factor method and no significant diagnosis $\times$ method interaction $(\mathrm{df}=2,2 ; \mathrm{F}=0.4,1.1 ; \mathrm{p}=0.68,0.34)$. The various studies did not consistently report other clinical characteristics.

\section{Quantitative Data Synthesis}

Figures S1-S3 (in the supplementary information) show the maxima of the several studies, which were included in the meta-analysis. For each study all maxima were taken into account to avoid any a priori assumptions. Four of the altogether 454 coordinates $(0.9 \%)$ were excluded from the analysis, because they were located more than $10 \mathrm{~mm}$ outside the brain. The quantitative meta-analyses identified numerous clusters above the respective ALE thresholds that are summarized in Table 2 and Table 3. Figures 2-4 display above-threshold voxels on an individual brain in Talairach space for the different patient groups. Firstly, we want to report results for the contrast amnestic MCI vs. control subjects (Figure 2, Table 2). Glucose utilization and perfusion were diminished in the inferior parietal lobules (BA 39/40), and the posterior cingulate cortex and precuneus (BA 23/31). Moreover, hypometabolism was detected in the left anterior superior insula (BA 15). Atrophy involved the left temporal pole/anterior superior temporal sulcus (BA 21/38), right amygdala, and gyrus rectus bilaterally (BA 11).

Results for the comparison AD vs. control subjects are illustrated in Figure 3 and Table 2. Reductions in glucose utilization and perfusion coincided in the inferior parietal lobules (BA 39/40), posterior superior temporal sulcus (BA 21/22), precuneus (BA 7/31), and posterior cingulate cortex (BA 23; nomenclature of Vogt, 2005). Glucose utilization was diminished additionally in the anterior medial frontal cortex, pregenual anterior cingulate gyrus (BA 9/10/32), and right inferior temporal sulcus (BA 20/21), whereas perfusion was reduced in the right frontal pol (BA 10), left posterior middle frontal gyrus (BA 8/9), and left hippocampal head. Atrophy as measured by MRI showed a different pattern. It involved a network consisting of both amygdalae, both anterior hippocampal formations, unci and (trans-)entorhinal areas (BA 28/34). On the right also the hippocampal body and tail were affected. Furthermore, the meta-analysis revealed atrophy in the left medial thalamus, posterior insula (BA 13), and left middle temporal gyrus/superior temporal sulcus (BA 21/22). 
The last analysis characterized the amnestic MCI patients in more detail. Namely it examined the prognostic and (potentially) therapeutically important question if one can judge from brain scans during the state of MCI whether the patient progresses/converts to AD (Figure 4, Table 2). The follow up period had on average a length of approximately two years (23.3 \pm 8.0 months; range 12-36 months). As a smaller number of studies was available, the three methods (FDGPET, perfusion, MRI) were not considered separately, rather pooled. Patients with MCI later progressing to $\mathrm{AD}$ (converter) showed seven significant above-threshold clusters if compared with control subjects, namely bilaterally in the vicinity of the parahippocampal gyrus/(trans-) entorhinal area, and hippocampal body (BA 28/34-36), in the angular and supramarginal gyrus (BA 39/40), the posterior cingulate gyrus and inferior precuneus (BA 23/31). For patients with stable MCI (non-converter) we detected a neural network consisting of the dorsal posterior cingulate cortex/inferior precuneus (BA 23/32) and the right gyrus rectus extending into the medial orbital gyrus (BA 11/13/14) in comparison with control subjects. Analyzing maxima from studies contrasting $\mathrm{MCI}$ converters vs. non-converters revealed a cluster mainly in the left inferior parietal lobule and precuneus (BA 7/31/39/40).

Because not all single studies investigating MCI converters and non-converters compared both groups directly, we applied another method to compare the ALE map of converters vs. control subjects with the ALE map of non-converters vs. control subjects. Recently, such a technique for making statistical comparisons between ALE meta-analysis maps was suggested to assess the difference between two ALE maps under the null hypothesis that differences between both sets of coordinates are uniformly distributed ('subtraction meta-analysis' according to Laird et al., 2005 and Ellison-Wright et al., 2008). Specifically, ALE maps from two sets of coordinates are subtracted from each other to yield an empirical difference map. The corresponding histogram is then tested against the histogram obtained from 1,000 randomly generated difference maps, thereby again applying a very conservative threshold to reduce type I errors. Results are illustrated in Figure 4 and Table 3. Patients with amnestic MCI later progressing to $\mathrm{AD}$ (converters) showed specific deficits bilaterally in the vicinity of the parahippocampal gyrus/(trans-)entorhinal area, and hippocampal body (BA 28/34-36), in the angular and supramarginal gyrus (BA 39/40), and right gyrus rectus/medial orbital gyrus (BA 11/13/14).

\section{Discussion}

We applied a systematic and quantitative meta-analytic approach to characterize the prototypical neural substrates of $\mathrm{AD} / \mathrm{amnestic} \mathrm{MCI}$ and to isolate neural markers predicting the conversion from amnestic MCI to AD. It revealed specifically for each imaging method the impaired neural networks for $\mathrm{AD}$ and $\mathrm{MCI}$. Results for $\mathrm{AD}$ agree with a previous comprehensive meta-analysis that calculated effect sizes for various predefined anatomical regions (Zakzanis et al., 2003). Because more relevant studies were now available, we could improve the meta-analytic approach decisively by including additionally MCI patients, investigating each imaging method separately, and applying a new meta-analytic method for imaging data enabling a data-driven approach (Fox et al., 2005; Turkeltaub et al., 2002). Because we included only those studies that used quantitative automated whole brain analysis and normalized results to a stereotactic space, presumptions for anatomical regions such as in region-of-interest studies could not confound results.

Our results together with previous imaging and histopathological studies show that $\mathrm{AD}$ affects limbic structures in the early and midcourse that are relatively spared in normal aging (Blennow et al., 2006; Braak and Braak, 1991a,b; Braak et al., 1996; Gauthier et al., 2006; Grieve et al., 2005; Hodges, 2006; Raz et al., 2004; Salat et al., 2004). Neurofibrillary tangles and neuropil threads occur initially in the transentorhinal cortex (transentorhinal stages I-II according to Braak), and subsequently spread into the entorhinal region/hippocampal formation proper 
(limbic stages III-IV) followed by destruction of virtually all isocortical association areas (isocortical stages V-VI) (Braak and Braak, 1991b, 1995; Braak et al., 1996; Hyman et al., 1984). Interestingly, these neurofibrillary tangles are tightly related to neuropsychological impairments and dementia severity in contrast to amyloid deposits (Arriagada et al., 1992; Asuni et al., 2007; Bierer et al., 1995; Bondareff et al., 1993; Caselli et al., 2006; Guillozet et al., 2003; Jellinger, 2006; Roberson et al., 2007). A recent study has shown that MCI is associated mainly with Braak stages II and III, between the transentorhinal and limbic stages, whereas the transition to AD occurs when neurofibrillary abnormalities spread beyond the medial temporal lobes (stages IV+) (Petersen et al., 2006). Our meta-analysis may support alterations in the (trans-)entorhinal area/hippocampal body specifically in converters, predicting progression from MCI to $\mathrm{AD}$. These alterations are related to atrophy as suggested by the results for amnestic MCI/AD vs. control subjects. Furthermore, our meta-analysis indicates that the inferior parietal lobules and precuneus are functionally affected in amnestic MCI converters, because results for parietal areas are most probably based on perfusion and glucose utilization studies (see again results for MCI/AD vs. control subjects). Parietal impairments might be caused by regional amyloid deposits as indicated by histopathological and imaging studies (Braak and Braak, 1991b; Chételat et al., 2008; Jack et al., 2008; Kemppainen et al., 2007), and by disconnection from the hippocampus through disruption of the cingulum bundle (so called diaschisis hypothesis) (Villain et al., 2008).

As discussed above one of the most important questions for imaging is the specific discrimination between converters, later progressing to $\mathrm{AD}$, and non-converters, particularly for treatment purposes (Chong and Sahadevan, 2005; Gauthier et al., 2006; Klafki et al., 2006; Schott et al., 2006). This analysis isolated differences in the vicinity of the parahippocampal, (trans-)entorhinal, and hippocampal areas, and in parietal regions (inferior parietal lobules and precuneus/posterior cingulate cortex). Because we pooled data across different imaging methods for this analysis to include a sufficient number of studies and enable high statistical power, we cannot relate these changes to one imaging method specifically. However, if one takes into account the results of the first method specific analysis (amnestic $\mathrm{MCI} / \mathrm{AD}$ vs. healthy controls) one might assume that parahippocampal, (trans-)entorhinal, and hippocampal effects are related mainly to atrophy, whereas parietal alterations represent reductions in perfusion and glucose metabolism. Reliable imaging indicators for conversion from MCI to AD have to comply with the following two conditions: (i) Brain regions have to be significantly affected in the contrast converters vs. non-converters. (ii) Brain regions must not be affected in non-converters in comparison with control subjects warranting specificity by excluding false positive predictions. Accordingly, our comprehensive meta-analysis may support the notion that atrophy in the (trans-)entorhinal area and hippocampus can predict which MCI patients will develop AD (Blennow et al., 2006; Chong and Sahadevan, 2005; den Heijer et al., 2006; Hua et al., 2008; Schott et al., 2006; Walker and Walker, 2005). Previous studies reported specific reductions of perfusion and glucose utilization in the posterior cingulate cortex and in the temporoparietal region in MCI converters (Blennow et al., 2006; Chong and Sahadevan, 2005; Walker and Walker, 2005; Wu and Small, 2006). Our data suggest that alterations in the inferior parietal lobules are the most reliable functional indicators for conversion to $\mathrm{AD}$, whereas changes in the posterior cingulate cortex/inferior precuneus may have to be regarded as unspecific as they were also observed in non-converters if compared with control subjects.

If one considers the neural correlates of fully developed $\mathrm{AD}$, our data indicate a substantial coincidence with those of amnestic MCI patients later converting to AD. Hence, our data support current concepts regarding MCI/AD as a continuous process (Dubois et al., 2007). Although AD involves, additionally to MCI, a frontomedian-thalamic network, such alterations are also observed in other types of dementia i. e. frontotemporal dementia, reducing their diagnostic specificity (de Jong et al., 2008; Schroeter et al., 2007b, 2008). The same holds true 
for alterations in the amygdalae, which also occur in semantic dementia (Schroeter et al., 2007b). Although, besides AD, semantic dementia and progressive non-fluent aphasia affect also the temporal lobes, alterations are located in the pole area in these diseases. According to present clinical criteria $\mathrm{AD}$ is mainly a diagnosis of exclusion and a definite diagnosis can only be made by neuropathology (Blennow et al., 2006; Reisberg, 2006). By defining its structural and functional neuroimaging markers, our meta-analysis may contribute to defining standardized (imaging) inclusion criteria for $\mathrm{AD}$ as suggested for future diagnostic systems such as the DSM-V (Dubois et al., 2007; Hyman, 2007; Reisberg, 2006).

Finally, we want to place neural alterations in a framework of cognitive neuropsychiatry by relating neural networks to cognitive dysfunctions (Halligan and David, 2001). AD is characterized in its earliest stage, MCI, by severe deficits in anterograde episodic memory with poor encoding and rapid forgetting of new material (Bäckman et al., 2001; Christensen et al., 1998; Hodges, 2006; Perry and Hodges, 2000). Encoding and consolidation of episodic and semantic memory, that might also be hampered, have been related to several 'bottleneck structures', namely the medial temporal lobes, the medial diencephalon, the basal forebrain and prefrontal regions (Brand and Markowitsch, 2005). It was proposed that two limbic circuits, the Papez circuit and amygdaloid or basolateral circuit, enable encoding and consolidation. Whereas the former circuit transfers information from short- to longterm memory, the latter one seems to be predominantly engaged in emotional processing and in encoding the emotional valence of experiences. Our meta-analysis indicates that its two most important parts are affected, namely the hippocampal-entorhinal complex in amnestic MCI, and later in AD the limbic thalamus in agreement with histopathological reports (Braak and Braak, 1991a, 1991b; Braak et al., 1996; Brand and Markowitsch, 2005). Moreover, MCI and AD involve the amygdala, another memory relevant structure (Brand and Markowitsch, 2005). Comparing patients with early-onset AD to control subjects the ALE analysis revealed additionally one cluster in the fornix, another relevant part of the Papez circuit (maximum at Talairach coordinates 1, 6, 0; cluster size $54 \mathrm{~mm}^{3}$, ALE value 0.005593).

Episodic memory retrieval is associated with the reciprocally interconnected posterior cingulate cortex and precuneus as well as lateral posterior parietal cortex beside prefrontal cortices (Cabeza and Nyberg, 2000; Cavanna and Trimble, 2006; Wagner et al., 2005). The meta-analysis shows hypometabolism/hypoperfusion in these structures in amnestic MCI and $\mathrm{AD}$, again in correspondence with histopathological data (Braak and Braak, 1991b; Braak et al., 1996). Episodic memory has per se autobiographical reference, since it entails the recollection of information that is linked to an individual's personal experience (Cavanna and Trimble, 2006). Accordingly, our meta-analysis revealed alterations in the anterior medial prefrontal cortex that is involved in self-monitoring/self-referential processing and in the amygdala (Cabeza and Jacques, 2007; Gallagher and Frith, 2003; Ochsner et al., 2004). AD patients are early impaired in tests of autobiographical memory in relation with hypometabolism in the precuneus, posterior cingulate and inferior parietal lobules (Eustache et al., 2004). The anterior medial frontal cortex (BA 9/32) has also been discussed as the key region for theory of mind or 'mentalizing', where mental states have to be attributed to self and other people, and which enables social cognition, together with the temporoparietal junction area (Frith and Frith, 2003; Gallagher and Frith, 2003). AD patients are impaired in such tasks (Cuerva et al., 2001; Verdon et al., 2007). Deficits in their facial emotion processing (Albert et al., 1991; Teng et al., 2007) might be related to a disturbed extended neural system for face perception, namely the amygdalae (Haxby et al., 2000). Furthermore, our metaanalysis shows that the left temporal pole is affected, which has been discussed as part of the semantic memory network (Martin and Chao, 2001).

By the time most patients are diagnosed with $\mathrm{AD}$, deficits in attention and executive abilities are usually apparent (Amieva et al., 2004; Baddley et al., 1991, 2001; Hodges, 2006; Kopelman, 
1991; Perry and Hodges, 1999; Pignatti et al., 2005; Sahakian et al., 1988). These capabilities are related to the anterior cingulate cortex and the inferior frontal junction area (Carter et al., 1998; Derrfuss et al., 2005; Paus, 2001; Ridderinkhof et al., 2004; Schroeter et al., 2002, 2003, 2004, 2007a; Vogt, 2005). Our meta-analysis identified alterations in these brain regions in $\mathrm{AD}$, namely hypometabolism in the anterior cingulate cortex and hypoperfusion in the left posterior middle frontal gyrus near the inferior frontal junction area. We did not find these networks in amnestic MCI in correspondence with histopathological studies and the observation that, although subjects later progressing to dementia have attentional/executive deficits if appropriate experimental tasks are administered, these deficits are overshadowed by amnesia (Bäckman et al., 2004, 2005; Braak and Braak, 1991b; Chen et al., 2001; Hodges, 2006; Tabert et al., 2006; Tales et al., 2005a,b). Visuo-spatial and perceptual symptoms usually follow in the wake of episodic memory and attentional deficits (Caine and Hodges, 2001; Hodges, 2006; Perry et al., 2000). Our meta-analysis revealed alterations in the inferior parietal lobules extending to the intraparietal sulcus and in the precuneus, regions processing visuospatial information and enabling spatially guided behavior (Cavanna and Trimble, 2006). Additionally, the hippocampus/parahippocampal cortex have been discussed in the context of spatial processing (Bird and Burgess, 2008; Epstein 2008). In agreement with preserved proper language functions in the early course of $\mathrm{AD}$ the meta-analysis did not reveal alterations in the respective network (Blair et al., 2007; Hodges, 2006). Recently, it has been suggested that episodic memory, theory of mind, navigation, and prospection rely on the same mesiotemporalfrontoparietal core network and are subcomponents of the more general abilities of 'selfprojection' (Buckner and Carroll, 2007) or 'scene construction' (Hassabis and Maguire, 2007). Obviously, AD affects this core network and disturbs its cognitive subcomponents (Buckner et al., 2005).

In agreement with the most prominent behavioral symptom, apathy, the meta-analysis and histopathological studies demonstrate frontomedian alterations in AD (Braak and Braak, 1991b; Hodges, 2006; Rosen et al., 2005). Our results suggest intact function in this area in amnestic MCI agreeing with the finding that prevalence of apathy increases with severity of dementia (Starkstein et al., 2006). Although insight is preserved early in the disease, it diminishes with its progression to AD leading to unawareness of cognitive deficits (anosognosia) (Ecklund-Johnson and Torres, 2005; Markova and Berrios, 2000; Salmon et al., 2006). This deficit may be related to the anterior medial frontal cortex/pregenual anterior cingulate together with the posterior cingulate cortex and temporoparietal junction area (Ecklund-Johnson and Torres, 2005; Hodges, 2006; Salmon et al., 2006). In contrast, AD patients note their emotional/behavioral difficulties (Ecklund-Johnson and Torres, 2005) leading presumably to a high rate of depression (Levy et al., 1996). Our results further confirm the assumption that decreased motivational-affective components of pain in AD may be related to the degeneration of the medial pain system (anterior cingulate cortex, medial thalamic nuclei/ intralaminar thalamic nuclei, amygdala, insula, hippocampus and prefrontal cortex; Scherder et al., 2003; Vogt, 2005).

Finally, we want to discuss the meta-analytic approach critically. Firstly, ALE is based on the assumption that the spatial uncertainty of peak coordinates is identical across the $\mathrm{x}-, \mathrm{y}-$ and $\mathrm{z}$ direction of the coordinate system as well as across all voxels in the brain. This is a simplifying assumption. However, as discussed by Eickhoff et al. (2009), modeling a variable spatial uncertainty along different directions and across different brain regions would require empirical uncertainty estimates for every region or voxel in the brain. To date, such data are not available. In line with Eickhoff et al. (2009), we would thus argue that in the absence of voxel-wise empirical data on spatial uncertainty, the most parsimonious model based on the most general assumption of Gaussianity should be applied. Secondly, results of any metaanalysis depend on the quality of the included data. Imaging meta-analyses are likely to be biased toward particular cortical areas, a problem referred to previously as 'literature or 
publication bias.' We tried to avoid this problem by including only studies that used quantitative automated whole brain analysis, whereas region-of-interest studies were generally excluded. Because our meta-analysis included maxima and not cluster sizes of the various studies, it extracted the prototypical, most characteristic neural networks for amnestic MCI/AD representing the brain regions that are consistently involved. Accordingly, single studies might have shown that the disorder may affect other brain structures and may be more diffuse than the present meta-analysis suggests. The other aforementioned limitations of our meta-analysis, specifically pooling across different imaging methods for the converters' analysis and potential medication effects onto perfusion and metabolism, should be addressed in future studies.

\section{Conclusion}

The meta-analysis characterizes the prototypical neural substrates of Alzheimer's disease and its prodromal stage amnestic mild cognitive impairment with a systematic and quantitative meta-analysis. It places Alzheimer's disease in cognitive neuropsychiatry by explaining clinical characteristics in terms of deficits to normal cognitive mechanisms and linking them to affected neural structures. By isolating predictive markers it contributes to standardized imaging inclusion criteria for Alzheimer's disease as suggested for future diagnostic systems.

\section{Supplementary Material}

Refer to Web version on PubMed Central for supplementary material.

\section{Acknowledgments}

Jane Neumann is supported by the NIH (Grant Number: R01 MH74457; PI: Peter Fox). The authors would like to thank Stefan Frisch for helpful suggestions during the preparation of the manuscript and Stefan Liebig for help in preparing the figures.

\section{References}

Albert MS, Cohen C, Koff E. Perception of affect in patients with dementia of the Alzheimer type. Arch Neurol 1991;48:791-795. [PubMed: 1898252]

American Psychiatric Association. Diagnostic and Statistical Manual of Mental Disorders. Vol. 3rd. American Psychiatric Press; Washington, DC: 1987.

American Psychiatric Association. Diagnostic and Statistical Manual of Mental Disorders. Vol. 4th. American Psychiatric Press; Washington, DC: 1994.

Amieva H, Phillips LH, Della Sala S, Henry JD. Inhibitory functioning in Alzheimer's disease. Brain 2004;127:949-964. [PubMed: 14645147]

Arriagada PV, Growdon JH, Hedley-Whyte ET, Hyman BT. Neurofibrillary tangles but not senile plaques parallel duration and severity of Alzheimer's disease. Neurology 1992;42:631-639. [PubMed: 1549228]

Asuni AA, Boutajangout A, Quartermain D, Sigurdsson EM. Immunotherapy targeting pathological tau conformers in a tangle mouse model reduces brain pathology with associated functional improvements. J Neurosci 2007;27:9115-9129. [PubMed: 17715348]

Baddeley AD, Bressi S, Della Sala S, Logie R, Spinnler H. The decline of working memory in Alzheimer's disease: A longitudinal study. Brain 1991;114:2521-2542. [PubMed: 1782529]

Baddeley AD, Baddeley HA, Bucks RS, Wilcock GK. Attentional control in Alzheimer's disease. Brain 2001;124:1492-1508. [PubMed: 11459742]

Bäckman L, Small BJ, Fratiglioni L. Stability of the preclinical episodic memory deficit in Alzheimer's disease. Brain 2001;124:96-102. [PubMed: 11133790]

Bäckman L, Jones S, Berger AK, Laukka EJ, Small BJ. Multiple cognitive deficits during the transition to Alzheimer's disease. J Intern Med 2004;256:195-204. [PubMed: 15324363] 
Bäckman L, Jones S, Berger AK, Laukka EJ, Small BJ. Cognitive impairment in preclinical Alzheimer's disease: A meta-analysis. Neuropsychology 2005;19:520-531. [PubMed: 16060827]

Bierer LM, Hof PR, Purohit DP, Carlin L, Schmeidler J, Davis KL, Perl DP. Neocortical neurofibrillary tangles correlate with dementia severity in Alzheimer's disease. Arch Neurol 1995;52:81-88. [PubMed: 7826280]

Bird CM, Burgess N. The hippocampus and memory: Insights from spatial processing. Nat Rev Neurosci 2008;9:182-194. [PubMed: 18270514]

Blair M, Marczinski CA, Davis-Faroque N, Kertesz A. A longitudinal study of language decline in Alzheimer's disease and frontotemporal dementia. J Int Neuropsychol Soc 2007;13:237-245. [PubMed: 17286881]

Blennow K, de Leon MJ, Zettenberg H. Alzheimer's disease. Lancet 2006;368:387-403. [PubMed: $16876668]$

Bondareff W, Mountjoy CQ, Wischik CM, Hauser DL, LaBree LD, Roth M. Evidence of subtypes of Alzheimer's disease and implications for etiology. Arch Gen Psychiatry 1993;50:350-356. [PubMed: 8489324]

Braak H, Braak E. Alzheimer's disease affects limbic nuclei of the thalamus. Acta Neuropathol 1991a; 81:261-268. [PubMed: 1711755]

Braak H, Braak E. Neuropathological stageing of Alzheimer-related changes. Acta Neuropathol 1991b; 82:239-259. [PubMed: 1759558]

Braak H, Braak E. Staging of Alzheimer's disease-related neurofibrillary changes. Neurobiol Aging 1995;16:271-284. [PubMed: 7566337]

Braak H, Braak E, Yilmazer D, de Vos RAI, Jansen ENH, Bohl J. Pattern of brain destruction in Parkinson's and Alzheimer's diseases. J Neural Transm 1996;103:455-490. [PubMed: 9617789]

Brand, M.; Markowitsch, HJ. Amnesia I: Clinical and anatomical issues. In: Farah, MJ.; Feinberg, TE., editors. Patient-based approaches to cognitive neuroscience. Vol. 2nd. M.I.T. Press; Cambridge, Massachusetts: 2005. p. 289-301.

Buckner RL, Snyder AZ, Shannon BJ, LaRossa G, Sachs R, Fotenos AF, Sheline YI, Klunk WE, Mathis CA, Morris JC, Mintun MA. Molecular, structural, and functional characterization of Alzheimer's disease: Evidence for a relationship between default activity, amyloid, and memory. J Neurosci 2005;25:7709-7717. [PubMed: 16120771]

Buckner RL, Carroll DC. Self-projection and the brain. Trends Cogn Sci 2007;11:49-57. [PubMed: 17188554]

Cabeza R, Nyberg L. Imaging cognition II: An empirical review of 275 PET and fMRI studies. J Cogn Neurosci 2000;12:1-47. [PubMed: 10769304]

Cabeza R, Jacques PS. Functional imaging of autobiographical memory. Trends Cogn Sci 2007;11:219_ 227. [PubMed: 17382578]

Caine D, Hodges JR. Heterogeneity of semantic and visuospatial deficits in early Alzheimer's disease. Neuropsychology 2001;15:155-164. [PubMed: 11324859]

Carter CS, Braver TS, Barch DM, Botvinick MM, Noll D, Cohen JD. Anterior cingulate cortex, error detection, and the online monitoring of performance. Science 1998;280:747-749. [PubMed: 9563953]

Caselli RJ, Beach TG, Yaari R, Reiman EM. Alzheimer's disease a century later. J Clin Psychiatry 2006;67:1784-1800. [PubMed: 17196061]

Cavanna AE, Trimble MR. The precuneus: A review of its functional anatomy and behavioural correlates. Brain 2006;129:564-583. [PubMed: 16399806]

Chau W, McIntosh AR. The Talairach coordinate of a point in the MNI space: How to interpret it. NeuroImage 2005;25:408-416. [PubMed: 15784419]

Chen P, Ratcliff G, Belle SH, Cauley JA, DeKosky ST, Ganguli M. Patterns of cognitive decline in presymptomatic Alzheimer disease: A prospective community study. Arch Gen Psychiatry 2001;58:853-858. [PubMed: 11545668]

Chételat G, Desgranges B, Landeau B, Mézenge F, Poline JB, de la Sayette V, Viader F, Eustache F, Baron JC. Direct voxel-based comparison between grey matter hypometabolism and atrophy in Alzheimer's disease. Brain 2008;131:60-71. [PubMed: 18063588] 
Chong MS, Sahadevan S. Preclinical Alzheimer's disease: Diagnosis and prediction of progression. Lancet Neurol 2005;4:576-579. [PubMed: 16109364]

Christensen H, Kopelman MD, Stanhope N, Lorentz L, Owen P. Rates of forgetting in Alzheimer dementia. Neuropsychologia 1998;36:547-557. [PubMed: 9705065]

Cuerva AG, Sabe L, Kuzis G, Tiberti C, Dorrego F, Starkstein SE. Theory of mind and pragmatic abilities in dementia. Neuropsych Neuropsych Behav Neurol 2001;14:153-158.

Cummings JL. Alzheimer's disease. New Engl J Med 2004;351:56-67. [PubMed: 15229308]

de Jong LW, van der Hiele K, Veer IM, Houwing JJ, Westendorp RGJ, Bollen ELEM, de Bruin PW, Middelkoop HAM, van Buchem MA, van der Grond J. Strongly reduced volumes of putamen and thalamus in Alzheimer's disease: An fMRI study. Brain 2008;131:3277-3285. [PubMed: 19022861]

den Heijer T, Geerlings MI, Hoebeek FE, Hofman A, Koudstaal PJ, Breteler MMB. Use of hippocampal and amygdalar volumes on magnetic resonance imaging to predict dementia in cognitively intact elderly people. Arch Gen Psychiatry 2006;63:57-62. [PubMed: 16389197]

Derrfuss J, Brass M, Neumann J, von Cramon DY. Involvement of the inferior frontal junction in cognitive control: Meta-analyses of switching and Stroop studies. Hum Brain Mapp 2005;25:22-34. [PubMed: 15846824]

Dubois B, Feldman HH, Jacova C, DeKosky ST, Barberger-Gateau P, Cummings J, Delacourte A, Galasko D, Gauthier S, Jicha G, Meguro K, O'Brien J, Pasquier F, Robert P, Rossor M, Salloway S, Stern Y, Visser PJ, Scheltens P. Research criteria for the diagnosis of Alzheimer's disease: Revising the NINCDS-ADRDA criteria. Lancet Neurol 2007;6:734-746. [PubMed: 17616482]

Ecklund-Johnson E, Torres I. Unawareness of deficits in Alzheimer's disease and other dementias: Operational definitions and empirical findings. Neuropsychol Rev 2005;15:147-166. [PubMed: 16328733]

Eickhoff SB, Laird AR, Grefkes C, Wang LE, Zilles K, Fox PT. Coordinate-based activation likelihood estimation meta-analysis of neuroimaging data: A random-effects approach based on empirical estimates of spatial uncertainty. Hum Brain Mapp. 2009in press

Ellison-Wright I, Glahn DC, Laird AR, Thelen SM, Bullmore E. Anatomy of first-episode and chronic schizophrenia: An anatomical likelihood estimation meta-analysis. Am J Psychiat 2008;165:10151023. [PubMed: 18381902]

Epstein RA. Parahippocampal and retrosplenial contributions to human spatial navigation. Trends Cogn Sci 2008;12:388-396. [PubMed: 18760955]

Eustache F, Piolino P, Giffard B, Viader F, De La Sayette V, Baron JC, Desgranges B. In the course of time: A PET study of the cerebral substrates of autobiographical amnesia in Alzheimer's disease. Brain 2004;127:1549-1560. [PubMed: 15102619]

Fox PT, Laird AR, Lancaster JL. Coordinate-based voxel-wise meta-analysis: Dividends of spatial normalization. Report of a virtual workshop. Hum Brain Mapp 2005;25:1-5. [PubMed: 15846826]

Frith U, Frith CD. Development and neurophysiology of mentalizing. Phil Trans R Soc Lond B 2003;358:459-473. [PubMed: 12689373]

Gallagher HL, Frith CD. Functional imaging of theory of mind. Trends Cogn Sci 2003;7:77-83. [PubMed: 12584026]

Gauthier S, Reisberg B, Zaudig M, Petersen RC, Ritchie K, Broich K, Belleville S, Brodaty H, Bennett D, Chertkow H, Cummings JL, de Leon M, Feldman H, Ganguli M, Hampel H, Scheltens P, Tierney MC, Whitehouse P, Winblad B. Mild cognitive impairment. Lancet 2006;367:1262-1270. [PubMed: 16631882]

Glahn DC, Laird AR, Ellison-Wright I, Thelen SM, Robinson JL, Lancaster JL, Bullmore E, Fox PT. A quantitative meta-analysis of voxel-based morphometry studies in schizophrenia: Application of anatomical likelihood estimation. Biol Psychiatry 2008;64:774-781. [PubMed: 18486104]

Grieve SM, Clark CR, Williams LM, Peduto AJ, Gordon E. Preservation of limbic and paralimbic structures in aging. Hum Brain Mapp 2005;25:391-401. [PubMed: 15852381]

Guillozet AL, Weintraub S, Mash DC, Mesulam MM. Neurofibrillary tangles, amyloid, and memory in aging and mild cognitive impairment. Arch Neurol 2003;60:729-736. [PubMed: 12756137]

Halligan PW, David AS. Cognitive neuropsychiatry: Towards a scientific psychopathology. Nat Rev Neurosci 2001;2:209-215. [PubMed: 11256082] 
Hassabis D, Maguire EA. Deconstructing episodic memory with construction. Trends Cogn Sci 2007;11:299-306. [PubMed: 17548229]

Haxby JV, Hoffmann EA, Gobbini MI. The distributed human neural system for face perception. Trends Cogn Sci 2000;4:223-233. [PubMed: 10827445]

Hirao K, Onishi T, Hirata Y, Yamashita F, Mori T, Moriguchi Y, Matsuda H, Nemoto K, Imabayashi E, Yamada M, Iwamoto T, Arima K, Asada T. The prediction of rapid conversion to Alzheimer's disease in mild cognitive impairment using regional cerebral blood flow SPECT. NeuroImage 2005;28:1014-1021. [PubMed: 16129627]

Hodges JR. Alzheimer's centennial legacy: Origins, landmarks and the current status of knowledge concerning cognitive aspects. Brain 2006;129:2811-2822. [PubMed: 17071920]

Hua X, Leow AD, Parikshak N, Lee S, Chiang MC, Toga AW, Jack CR, Weiner MW, Thompson PM. Tensor-based morphometry as a neuroimaging biomarker for Alzheimer's disease: An MRI study of 676 AD, MCI, and normal subjects. NeuroImage 2008;43:458-469. [PubMed: 18691658]

Huang C, Wahlund LO, Almkvist O, Elehu D, Svensson L, Jonsson T, Winblad B, Julin P. Voxel- and VOI-based analysis of SPECT CBF in relation to clinical and psychological heterogeneity of mild cognitive impairment. NeuroImage 2003;19:1137-1144. [PubMed: 12880839]

Hyman SE. Can neuroscience be integrated into the DSM-V? Nat Rev Neurosci 2007;8:725-732. [PubMed: 17704814]

Hyman BT, van Hoesen GW, Damasio AR, Barnes CL. Alzheimer's disease: Cell-specific pathology isolates the hippocampal formation. Science 1984;225:1168-1170. [PubMed: 6474172]

Ishii K, Sasaki H, Kono AK, Miyamoto N, Fukuda T, Mori E. Comparison of gray matter and metabolic reduction in mild Alzheimer's disease using FDG-PET and voxel-based morphometric MR studies. Eu J Nucl Med Mol Imaging 2005;32:959-963.

Jack CR, Lowe VJ, Senjem ML, Weigand SD, Kemp BJ, Shiung MM, Knopman DS, Boeve BF, Klunk WE, Mathis CA, Petersen RC. ${ }^{11} \mathrm{C} \mathrm{PiB}$ and structural MRI provide complementary information in imaging of Alzheimer's disease and amnestic mild cognitive impairment. Brain 2008;131:665-680. [PubMed: 18263627]

Jellinger KA. Clinicopathological analysis of dementia disorders in the elderly - An update. J Alzheimer Dis 2006;9:61-70.

Kemppainen NM, Aalto S, Wilson IA, Nagren K, Helin S, Brück A, Oikonen V, Kailajärvi M, Scheinin M, Viitanen M, Parkkola R, Rinne JO. PET amyloid ligand $\left[{ }^{11} \mathrm{C}\right]$ PIB uptake is increased in mild cognitive impairment. Neurology 2007;68:1603-1606. [PubMed: 17485647]

Klafki HW, Staufenbiel M, Kornhuber J, Wiltfang J. Therapeutic approaches to Alzheimer's disease. Brain 2006;129:2840-2855. [PubMed: 17018549]

Kogure D, Matsuda H, Onishi T, Asada T, Uno M, Kunihiro T, Nakano S, Takasaki M. Longitudinal evaluation of early Alzheimer's disease using brain perfusion SPECT. J Nucl Med 2000;41:11551162. [PubMed: 10914904]

Kopelman MD. Frontal dysfunction and memory deficits in the alcoholic Korsakoff syndrome and Alzheimer-type dementia. Brain 1991;114:117-137. [PubMed: 1998878]

Laird AR, Fox PM, Price CJ, Glahn DC, Uecker AM, Lancaster JL, Turkeltaub PE, Kochunov P, Fox PT. ALE meta-analysis: Controlling the false discovery rate and performing statistical contrasts. Hum Brain Mapp 2005;25:155-164. [PubMed: 15846811]

Levy ML, Miller BL, Cummings JL, Fairbanks LA, Craig A. Alzheimer disease and frontotemporal dementias. Behavioral distinctions Arch Neurol 1996;53:687-690.

Markova, IS.; Berrios, GE. Insight into memory deficits. In: Berrios, GE.; Hodges, JR., editors. Memory disorders in psychiatric practice. Cambridge University Press; Cambridge: 2000. p. 204-233.

Martin A, Chao LL. Semantic memory and the brain: Structure and processes. Curr Opin Neurobiol 2001;11:194-201. [PubMed: 11301239]

McKhann G, Drachman D, Folstein M, Katzman R, Price D, Stadlan EM. Clinical diagnosis of Alzheimer's disease: Report of the NINCDS-ADRDA work group under the auspices of department of health and human services task force on Alzheimer's disease. Neurology 1984;34:939-944. [PubMed: 6610841] 
Moher D, Cook DJ, Eastwood S, Olkin I, Rennie D, Stroup DF. Improving the quality of reports of metaanalyses of randomised controlled trials: the QUOROM statement. Lancet 1999;354:1896-1900. [PubMed: 10584742]

Nestor PJ, Graham NL, Fryer TD, Williams GB, Patterson K, Hodges JR. Progressive non-fluent aphasia is associated with hypometabolism centred on the left anterior insula. Brain 2003;126:2406-2418. [PubMed: 12902311]

Ochsner KN, Knierim K, Ludlow DH, Hanelin J, Ramachandran T, Glover G, Mackey SC. Reflecting upon feelings: An fMRI study of neural systems supporting the attribution of emotion to self and other. J Cogn Neurosci 2004;16:1746-1772. [PubMed: 15701226]

Paus T. Primate anterior cingulate cortex: Where motor control, drive and cognition interface. Nat Rev Neurosci 2001;2:417-424. [PubMed: 11389475]

Pennanen C, Testa C, Laakso MP, Hallikainen M, Helkala EL, Hänninen T, Kivipelto M, Könönen M, Nissinen A, Tervo S, Vanhanen M, Vanninen R, Frisoni GB, Soininen H. A voxel based morphometry study on mild cognitive impairment. J Neurol Neurosurg Psychiatry 2005;76:11-14. [PubMed: 15607988]

Perry RJ, Hodges JR. Attention and executive deficits in Alzheimer's disease: A critical review. Brain 1999;122:383-404. [PubMed: 10094249]

Perry RJ, Hodges JR. Differentiating frontal and temporal variant frontotemporal dementia from Alzheimer's disease. Neurology 2000;54:2277-2284. [PubMed: 10881252]

Perry RJ, Watson P, Hodges JR. The nature and staging of attention dysfunction in early (minimal and mild) Alzheimer's disease: Relationship to episodic and semantic memory impairment. Neuropsychologia 2000;38:252-271. [PubMed: 10678692]

Petersen RC, Smith GE, Waring SC, Ivnik RJ, Tangalos EG, Kokmen E. Mild cognitive impairment Clinical characterization and outcome. Arch Neurol 1999;56:303-308. [PubMed: 10190820]

Petersen RC, Doody R, Kurz A, Mohs RC, Morris JC, Rabins PV, Ritchie K, Rossor M, Thal L, Winblad B. Current concepts in mild cognitive impairment. Arch Neurol 2001a;58:1985-1992. [PubMed: 11735772]

Petersen RC, Stevens JC, Ganguli M, Tangalos EG, Cummings JL, DeKosky ST. Practice parameter: Early detection of dementia: Mild cognitive impairment (an evidence-based review) - Report of the Quality Standards Subcommittee of the American Academy of Neurology. Neurology 2001b; 56:1133-1142. [PubMed: 11342677]

Petersen RC. Mild cognitive impairment as a diagnostic entity. J Intern Med 2004;256:183-194. [PubMed: 15324362]

Petersen RC, Parisi JE, Dickson DW, Johnson KA, Knopman DS, Boeve BF, Jicha GA, Ivnik RJ, Smith GE, Tangalos EG, Braak H, Kokmen E. Neuropathologic features of amnestic mild cognitive impairment. Arch Neurol 2006;63:665-672. [PubMed: 16682536]

Pignatti R, Rabuffetti M, Imbornone E, Mantovani F, Alberoni M, Farina E, Canal N. Specific impairments of selective attention in mild Alzheimer's disease. J Clin Exp Neuropsychol 2005;27:436-448. [PubMed: 15962690]

Raz N, Gunning-Dixon F, Head D, Rodrigue KM, Williamson A, Acker JD. Aging, sexual dimorphism, and hemispheric asymmetry of the cerebral cortex: Replicability of regional differences in volume. Neurobiol Aging 2004;25:377-396. [PubMed: 15123343]

Reisberg B. Diagnostic criteria in dementia: A comparison of current criteria, research challenges, and implications for DSM-V. J Geriat Psych Neurol 2006;19:137-146.

Ridderinkhof KR, Ullsperger M, Crone EA, Nieuwenhuis S. The role of the medial frontal cortex in cognitive control. Science 2004;306:443-447. [PubMed: 15486290]

Roberson ED, Scearce-Levie K, Palop JJ, Yan F, Cheng IH, Wu T, Gerstein H, Yu GQ, Mucke L. Reducing endogenous tau ameliorates amyloid $\beta$-induced deficits in an Alzheimer's disease mouse model. Science 2007;316:750-754. [PubMed: 17478722]

Rosen HJ, Allison SC, Schauer GF, Gorno-Tempini ML, Weiner MW, Miller BL. Neuroanatomical correlates of behavioural disorders in dementia. Brain 2005;128:2612-2625. [PubMed: 16195246]

Sahakian BJ, Morris RG, Evenden JL, Heald A, Levy R, Philpot M, Robbins TW. A comparative study of visuospatial memory and learning in Alzheimer-type dementia and Parkinson's disease. Brain 1988;111:695-718. [PubMed: 3382917] 
Salat DH, Buckner RL, Snyder AZ, Greve DN, Desikan RSR, Busa E, Morris JC, Dale AM, Fischl B. Thinning of the cerebral cortex in aging. Cereb Cortex 2004;14:721-730. [PubMed: 15054051]

Salmon E, Collette F, Degueldre C, Lemaire C, Franck G. Voxel-based analysis of confounding effects of age and dementia severity on cerebral metabolism in Alzheimer's disease. Hum Brain Mapp 2000;10:39-48. [PubMed: 10843517]

Salmon E, Perani D, Herholz K, Marique P, Kalbe E, Holthoff V, Delbeuck X, Beuthien-Baumann B, Pelati O, Lespagnard S, Collette F, Garraux G. Neural correlates of anosognosia for cognitive impairment in Alzheimer's disease. Hum Brain Mapp 2006;27:588-597. [PubMed: 16247783]

Scherder EJA, Sergeant JA, Swaab DF. Pain processing in dementia and its relation to neuropathology. Lancet Neurol 2003;2:677-686. [PubMed: 14572736]

Schott JM, Kennedy J, Fox NC. New developments in mild cognitive impairment and Alzheimer's disease. Curr Opin Neurol 2006;19:552-558. [PubMed: 17102693]

Schroeter ML, Zysset S, Kupka T, Kruggel F, von Cramon DY. Near-infrared spectroscopy can detect brain activity during a color-word matching Stroop task in an event-related design. Hum Brain Mapp 2002;17:61-71. [PubMed: 12203689]

Schroeter ML, Zysset S, Kruggel F, von Cramon DY. Age-dependency of the hemodynamic response as measured by functional near-infrared spectroscopy. NeuroImage 2003;19:555-564. [PubMed: 12880787]

Schroeter ML, Zysset S, Wahl MM, von Cramon DY. Prefrontal activation due to Stroop interference increases during development - An event-related fNIRS study. NeuroImage 2004;23:1317-1325. [PubMed: 15589096]

Schroeter ML, Cutini S, Wahl MM, Scheid R, von Cramon DY. Neurovascular coupling is impaired in cerebral microangiopathy - An event-related Stroop study. NeuroImage 2007a;34:26-34. [PubMed: 17070070]

Schroeter ML, Raczka K, Neumann J, von Cramon DY. Towards a nosology for frontotemporal lobar degenerations - A meta-analysis involving 267 subjects. NeuroImage 2007b;36:497-510. [PubMed: 17478101]

Schroeter ML, Raczka K, Neumann J, von Cramon DY. Neural networks in frontotemporal dementia A meta-analysis. Neurobiol Aging 2008;29:418-426. [PubMed: 17140704]

Starkstein SE, Jorge R, Mizrahi R, Robinson RG. A prospective longitudinal study of apathy in Alzheimer's disease. J Neurol Neurosurg Psychiatry 2006;77:8-11. [PubMed: 16361584]

Tabert MH, Manly JJ, Liu X, Pelton GH, Rosenblum S, Jacobs M, Zamora D, Goodkind M, Bell K, Stern Y, Devanand DP. Neuropsychological prediction of conversion to Alzheimer disease in patients with mild cognitive impairment. Arch Gen Psychiatry 2006;63:916-924. [PubMed: 16894068]

Tales A, Haworth J, Nelson S, Snowden R, Wilcock G. Abnormal visual search in mild cognitive impairment and Alzheimer's disease. Neurocase 2005a;11:80-84. [PubMed: 15804928]

Tales A, Snowden R, Haworth J, Wilcock G. Abnormal spatial and non-spatial cueing effects in mild cognitive impairment and Alzheimer's disease. Neurocase 2005b;11:85-92. [PubMed: 15804929]

Teng E, Lu PH, Cummings JL. Deficits in facial emotion processing in mild cognitive impairment. Dement Geriatr Cogn Disord 2007;23:271-279. [PubMed: 17351319]

Turkeltaub PE, Eden GF, Jones KM, Zeffiro TA. Meta-analysis of the functional neuroanatomy of singleword reading: Method and validation. NeuroImage 2002;16:765-780. [PubMed: 12169260]

Verdon CM, Fossati P, Verny M, Dieudonne B, Teillet L, Nadel J. Social cognition: An early impairment in dementia of the Alzheimer type. Alzheimer Dis Assoc Disord 2007;21:25-30. [PubMed: 17334269]

Villain N, Desgranges B, Viader F, de la Sayette V, Mézenge F, Landeau B, Baron JC, Eustache F, Chételat G. Relationships between hippocampal atrophy, white matter disruption, and gray matter hypometabolism in Alzheimer's disease. J Neurosci 2008;28:6174-6181. [PubMed: 18550759]

Vogt BA. Pain and emotion interactions in subregions of the cingulate gyrus. Nat Rev Neurosci 2005;6:533-544. [PubMed: 15995724]

Wagner AD, Shannon BJ, Kahn I, Buckner RL. Parietal lobe contributions to episodic memory retrieval. Trends Cogn Sci 2005;9:445-453. [PubMed: 16054861]

Walker Z, Walker RWH. Imaging in neurodegenerative disorders: Recent studies. Curr Opin Psychiatry 2005;18:640-646. [PubMed: 16639088] 
World Health Organization. The ICD-10 classification of mental and behavioural disorders: Diagnostic criteria for research. World Health Organization; Geneva: 1993.

Wu W, Small SA. Imaging the earliest stages of Alzheimer's disease. Curr Alzheimer Res 2006;3:529_ 539. [PubMed: 17168652]

Zakzanis KK, Graham SJ, Campbell Z. A meta-analysis of structural and functional brain imaging in dementia of the Alzheimer's type: A neuroimaging profile. Neuropsychol Rev 2003;13:1-18. [PubMed: 12691498]

\section{Abbreviations}

AD

Alzheimer's disease

ALE

anatomical likelihood estimate

DSM

Diagnostic and Statistical Manual of Mental Disorders

FDG-PET

${ }^{18}$ F-fluorodeoxyglucose-PET

MCI

amnestic mild cognitive impairment

MNI

Montreal Neurological Institute

MRI

magnetic resonance imaging

PET

positron emission tomography

SPECT

single photon emission computed tomography 


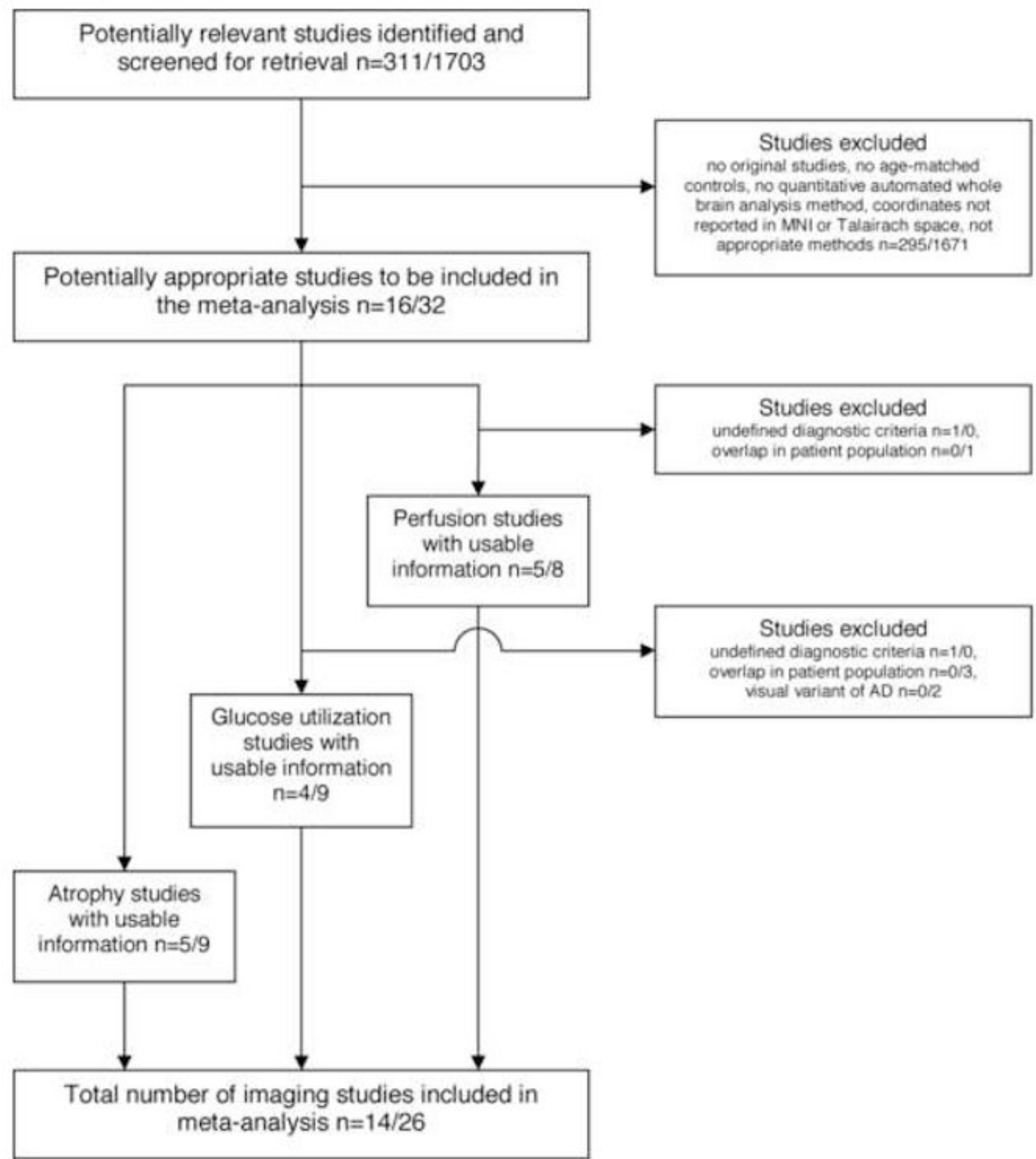

Figure 1.

Summary of the meta-analysis flow according to the QUOROM statement (Moher et al., 1999). Number of studies reported for mild cognitive impairment/Alzheimer's disease (AD). 


\section{$\mathrm{MCl}$ vs. Control}
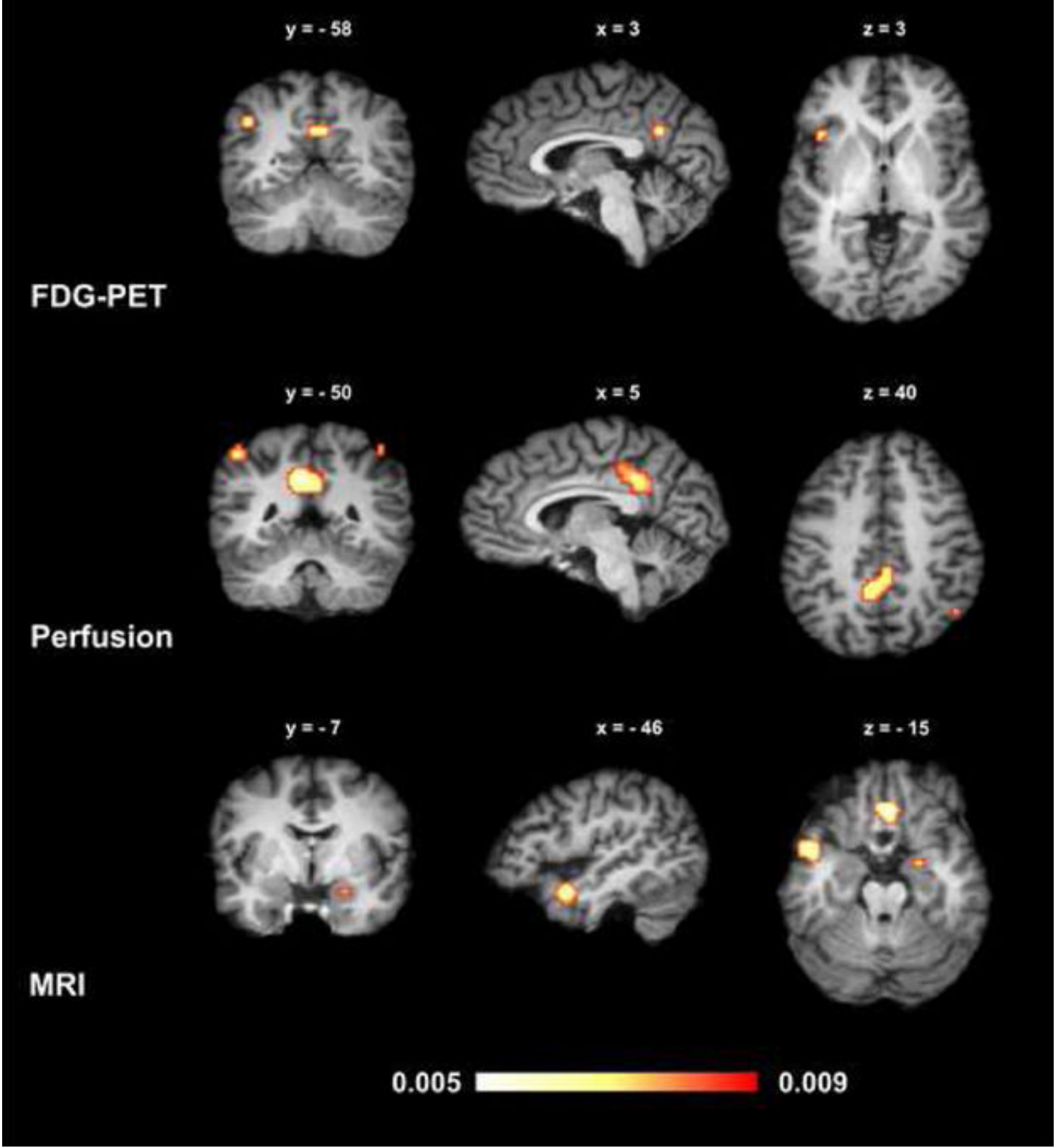

Figure 2.

Results of the quantitative meta-analyses (anatomical likelihood estimates) for amnestic mild cognitive impairment (MCI). Reductions of glucose utilization (FDG-PET,

fluorodeoxyglucose positron emission tomography), of perfusion or atrophy (MRI, magnetic resonance imaging). Left side is left. 


\section{AD vs. Control}

$y=-59$

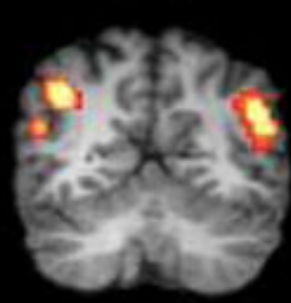

FDG-PET

$y=-24$

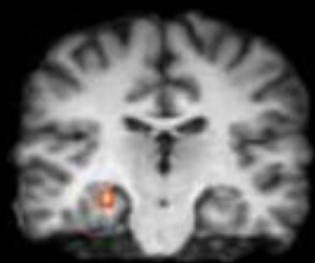

Perfusion

$y=-11$

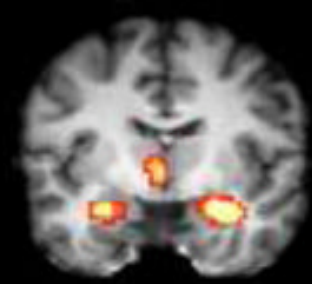

$x=2$

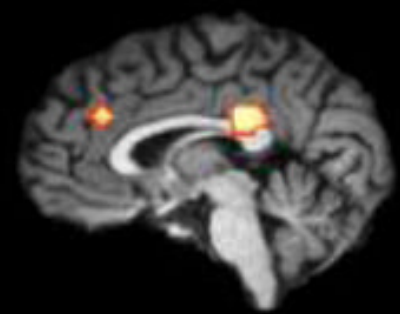

.

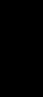
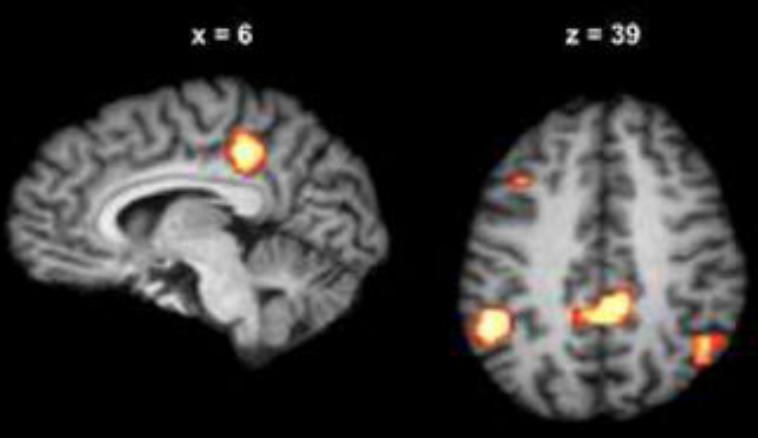

$x=30$
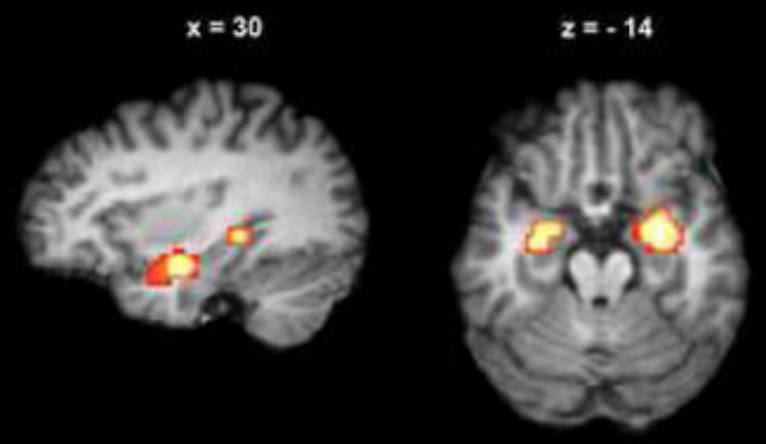

MRI

\subsection{6}

0.013

Figure 3.

Results of the quantitative meta-analyses (anatomical likelihood estimates) for Alzheimer's disease (AD). Reductions of glucose utilization (FDG-PET, fluorodeoxyglucose positron emission tomography), of perfusion or atrophy (MRI, magnetic resonance imaging). Left side is left. 


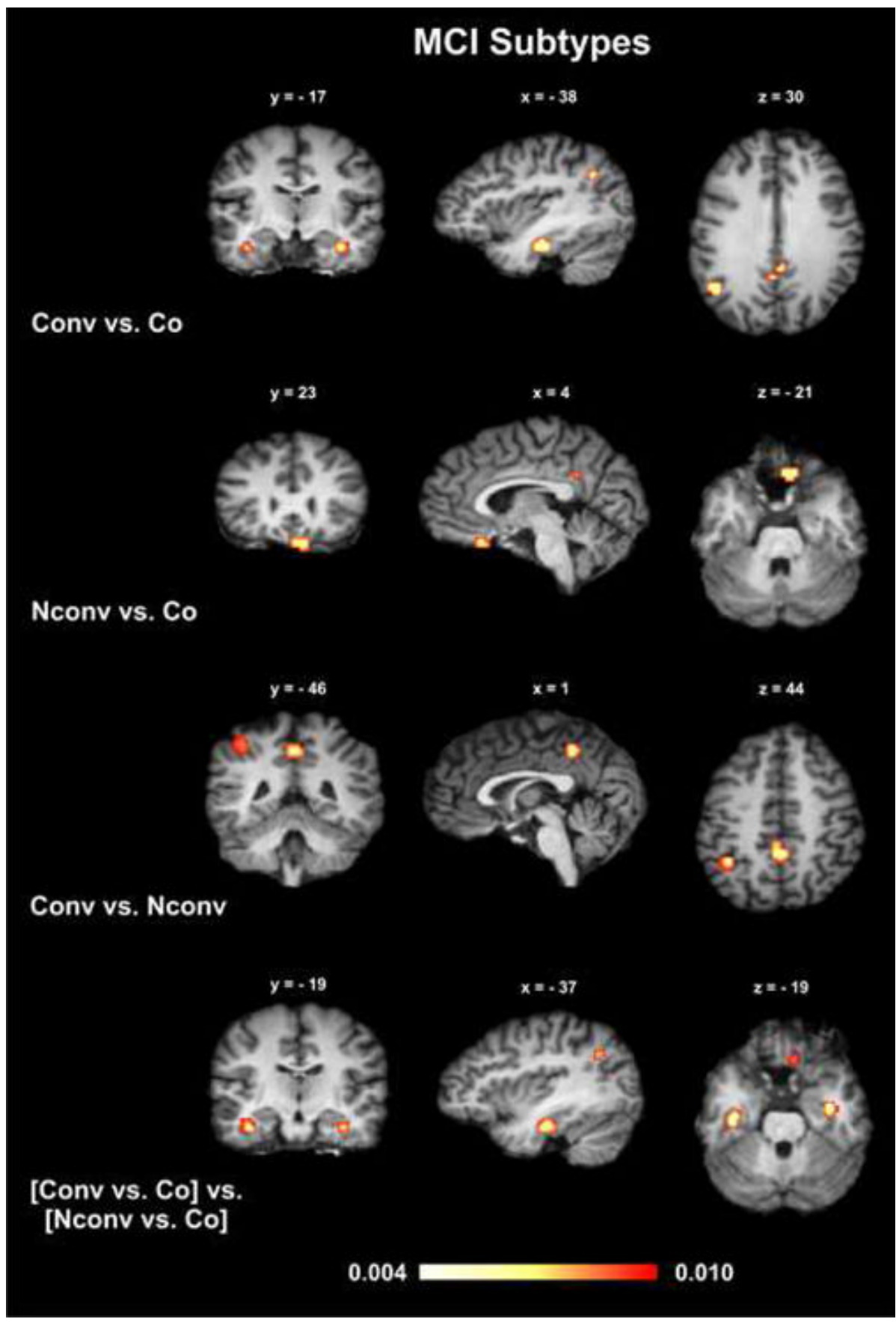

Figure 4.

Prediction of Alzheimer's disease. Neural impairments in converters that developed from mild amnestic cognitive impairment (MCI) to Alzheimer's disease later (Conv), and non-converters with stable mild cognitive impairment (Nconv) according to the quantitative meta-analyses (anatomical likelihood estimates, ALE). Co control subjects. First three upper rows ALE maps for contrasts in the single studies. Lower row comparison between the first and second ALE map. Studies reporting reductions of glucose utilization, of perfusion or atrophy were pooled. Left side is left. 


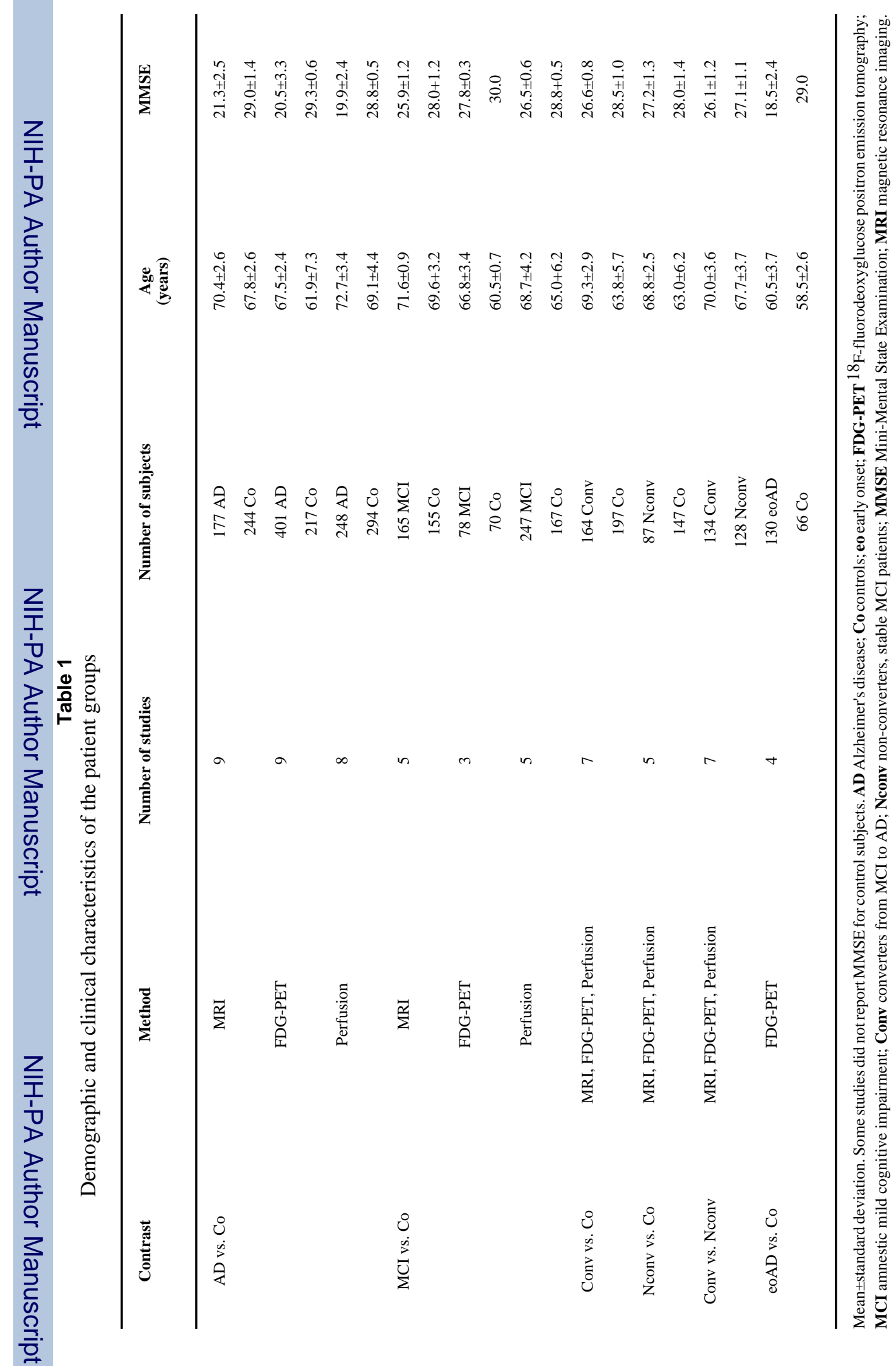




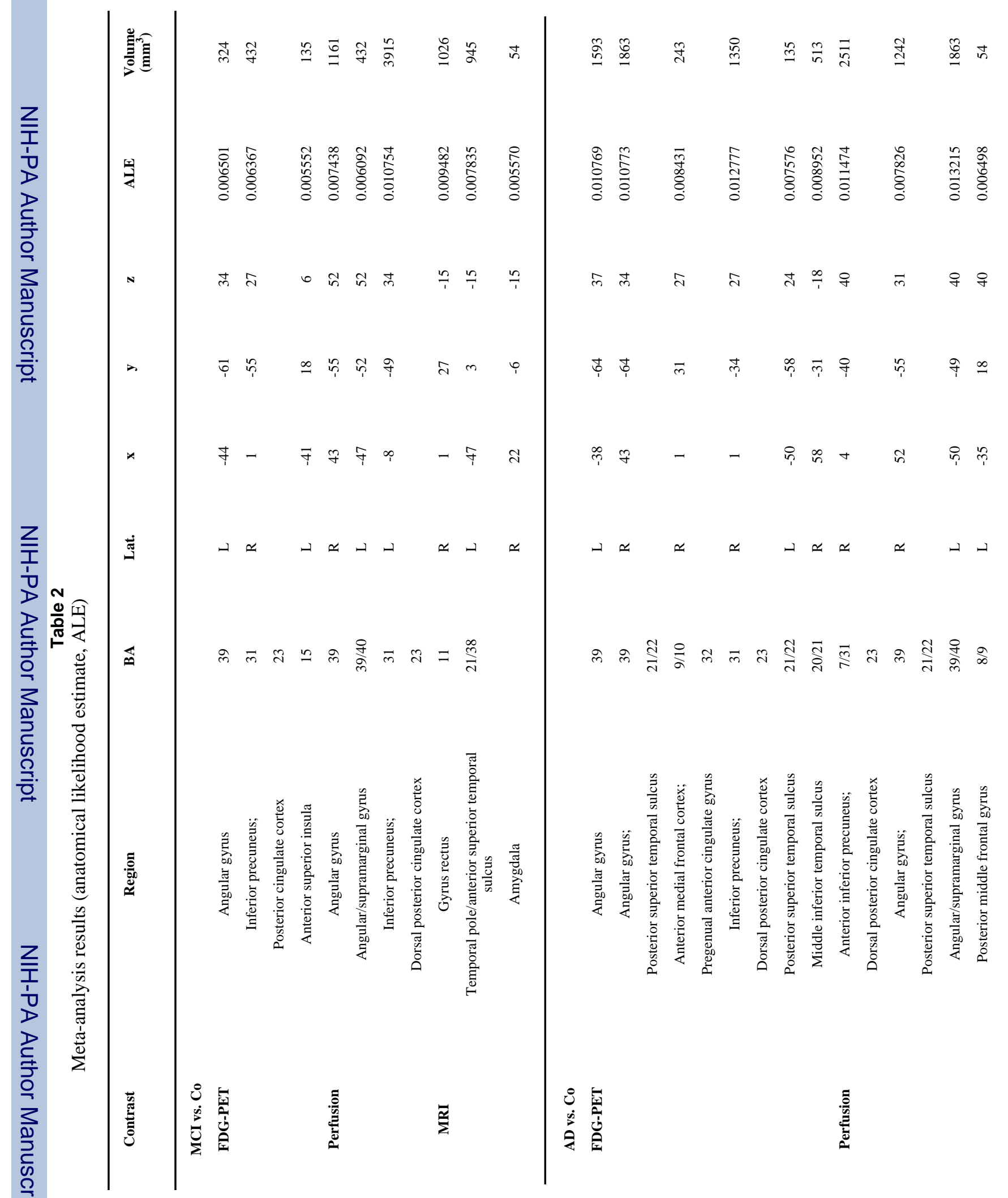




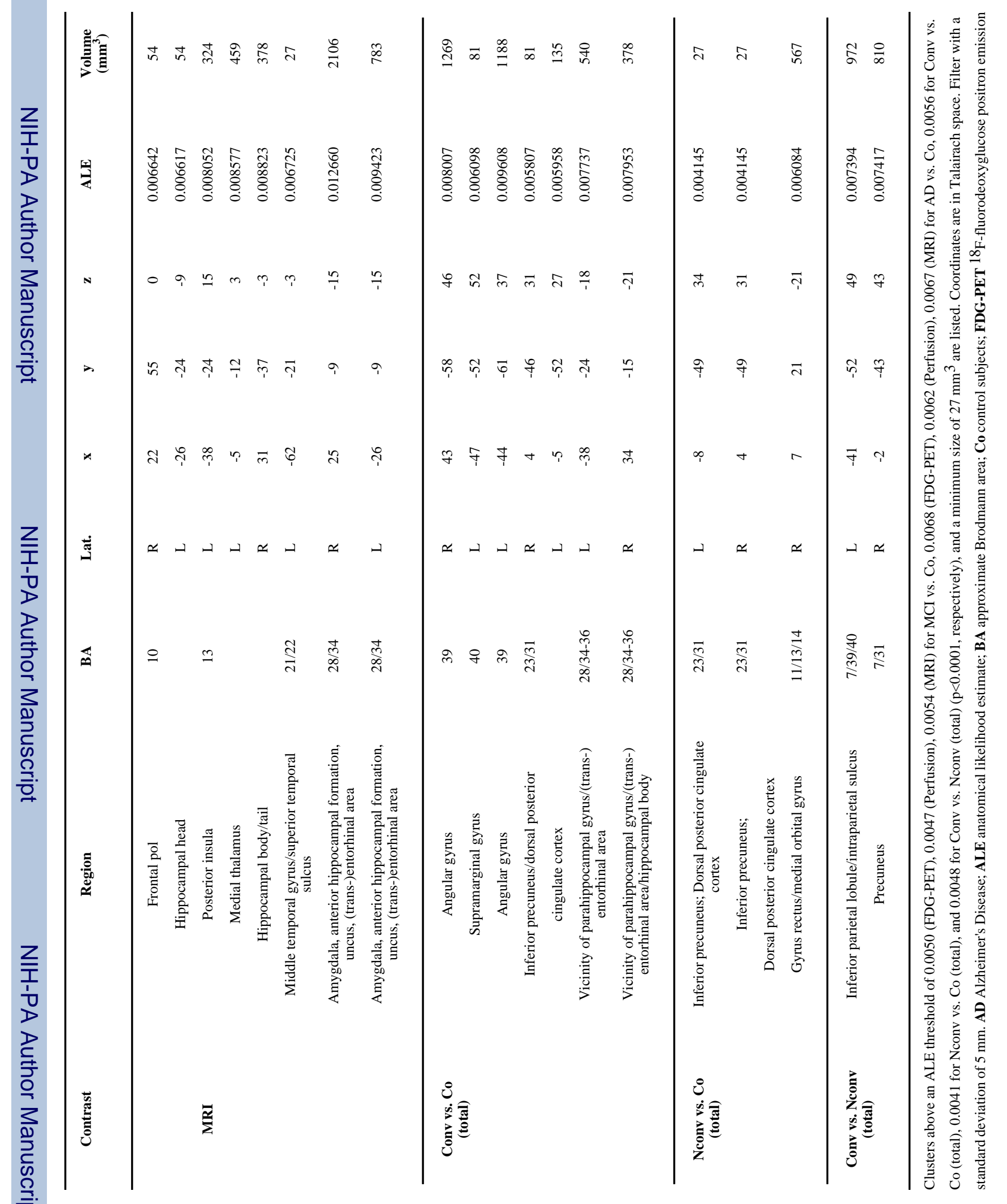




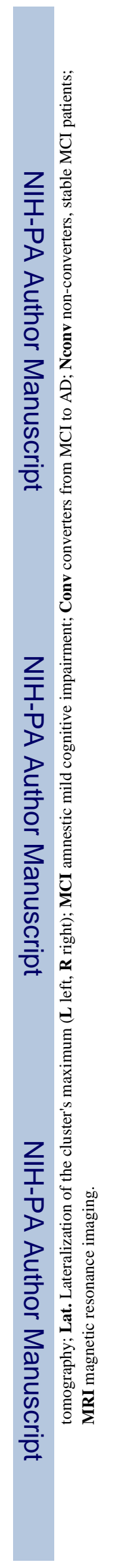

Page 24

Neuroimage. Author manuscript; available in PMC 2010 October 1. 


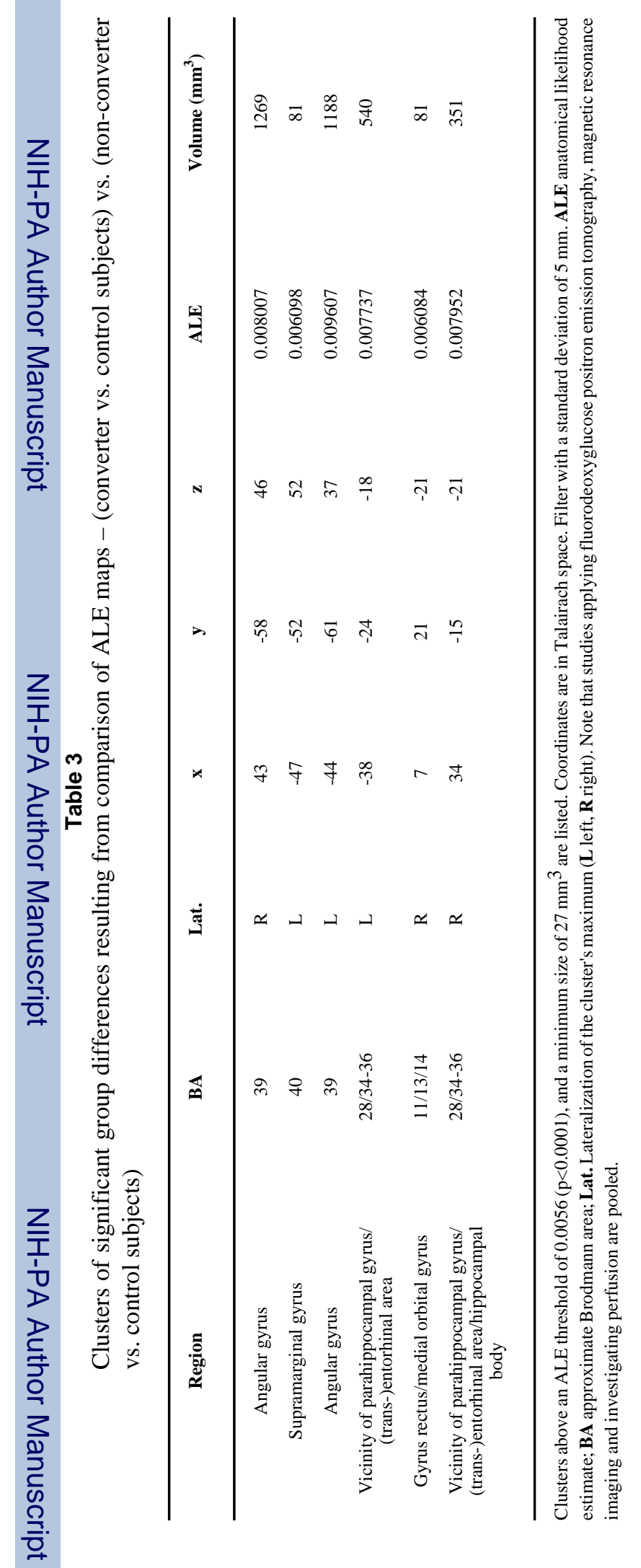

Neuroimage. Author manuscript; available in PMC 2010 October 1. 